\title{
The effectiveness of zoledronic acid and ibandronic acid as therapy for bone metastases in multiple myeloma: A systematic review
}

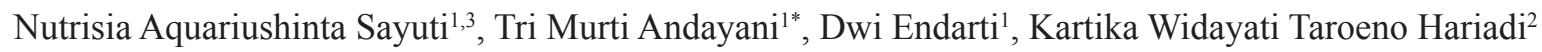 \\ ${ }^{1}$ Doctoral Program, Faculty of Pharmacy, Universitas Gadjah Mada, Yogyakarta, Indonesia. \\ ${ }^{2}$ Division of Hematology and Medical Oncology, Department of Internal Medicine, Faculty of Medicine, Public Health, and Nursing, Universitas Gadjah \\ Mada Dr. Sardjito Hospital, Yogyakarta, Indonesia. \\ ${ }^{3}$ Indonesian Herbal Medicine Department, Health Polytechnic of Surakarta, Ministry of Health Indonesia, Jakarta, Indonesia.
}

\section{ARTICLE INFO \\ Received on: 05/05/2019 \\ Accepted on: 09/08/2019 \\ Available online: 04/11/2019}

Key words:

Effectiveness,

zoledronic acid,

ibandronic acid,

multiple myeloma.

\begin{abstract}
Zoledronic acid and ibandronic acid are used in preventing skeletal-related event (SRE) in multiple myeloma (MM). Both drugs were listed in the Indonesian formulary. There was no available head-to-head comparative study, hence the need for a systematic review. The purpose of this systematic review was to describe the effectiveness of intravenous zoledronic and ibandronic acids in preventing SRE. The search for articles was conducted on accessible databases with the potential to provide relevant research material such as PUBMED, EBSCOhost, and ScienceDirect. The articles were limited to randomized controlled trials on both drugs in MM patients, published between 1980 and 2018. The outcomes were SRE, progression-free survival (PFS), overall survival (OS), and adverse event (AE). Thirteen articles were selected. According to the results obtained, the effectiveness of zoledronic acid in preventing SRE was superior to placebo or clodronic acid but not superior to denosumab and pamidronic acid. Ibandronic acid was not superior to placebo or pamidronic acid. The effectiveness of both drugs in preventing SRE was directly proportional to PFS and OS. In conclusion, zoledronic acid was superior to ibandronic acid, but with more occurrence of AE. However, the AE could be reduced by prolonging the duration of the drug use.
\end{abstract}

\section{INTRODUCTION}

Bone metastases are common occurrence in people with multiple myeloma (MM), which could cause skeletal-related events (SRE) such as fractures, spinal cord compression, need for radiotherapy and bone surgery (Union for International Cancer Control, 2016). According to Geng et al. (2015), there is a need for therapy considering the fact that these conditions affect the quality of life of the patients.

The bisphosphonate compounds have been found to be effective in the treatment symptomatic of bone disease. These compounds do not only prevent bone loss but also reduce musculoskeletal symptoms (Saroja and Ram, 2017). Also, in clinical practice, they are used for MM patients at stage I with

\footnotetext{
*Corresponding Author

Tri Murti Andayani, Doctoral Program, Faculty of Pharmacy, Universitas Gadjah Mada, Yogyakarta, Indonesia.

E-mail:trimurtia@yahoo.com
}

annual skeletal surveys, bone densitometry, and other metabolic tests (NCCN, 2018). Zoledronic acid and ibandronic acid given intravenously are the bisphosphonate compounds included in the Indonesian National Formulary.

Zoledronic acid is a third-generation aminobisphosphonate, which is stronger than the non-nitrogen bisphosphonates such as etidronate and clodronate (Alegre et al., 2013). Also, Gabbert et al. (2014) and Weide et al. (2010) reported that the Zoledronic acid is recommended in several therapeutic guidelines for MM in preventing SRE; however, it often comes with the osteonecrosis of the jaw (ONJ) and the incidence of kidney disorders as an adverse event (AE). Then, the ibandronic acid is used in treating hypercalcemia in solid tumors (Alegre et al., 2013). The European Union in 2003, approved the use of zoledronic acid in treating metastatic breast cancer, inhibit osteoclast activity and resorption of bone which causes apoptosis. The adverse effects of using ibandronic acid include diarrhea, nausea, and kidney toxicity. According to Geng et al. (2015), the most signifiant risks are abdominal pain and ONJ. 
However, in the occurrence of ONJ, the use of both drugs must be stopped, which could be continued once the patient recovers. Also, there is a need for the determination of creatinine serum levels, assessment of clinical symptoms, and conducting monthly blood tests as long as the drugs are in use. Other adverse drug reactions, reported according to Alegre et al. (2013), include nausea, vomiting, flu-like symptoms, arthromyalgia, bone pain, and hypocalcemia.

Also, there is a need for the assessment of the effectiveness of these drugs on SRE prevention, overall survival (OS), progression-free survival (PFS), and safety. This is usually a major concern for Indonesian clinicians considering the fact that the cost of both drugs is borne by the government. This systematic review, therefore, was a background to the evaluation of the effectiveness of zoledronic and ibandronic acids used during bone metastases therapy in MM. The aim of this systematic review was to describe the effectiveness of intravenous (IV) zoledronic and ibandronic acids.

\section{MATERIALS AND METHODS}

\section{Criteria for articles in the systematic review}

\section{Research types of the article}

The study involved the selection of articles based on randomized controlled trial with zoledronic acid or ibandronic acid as the intervention drugs during MM. The other drugs such as calcium and vitamin D supplements were included in the drugs given to subjects with zoledronic or ibandronic acids, as well as the comparators. Hence, the primary outcome was the incidence of SRE or PFS or OS, while the secondary was the AE. However, articles with other therapies different from bisphosphonate compounds were excluded in this research. The PRISMA performed is shown in Figure 1.

\section{Participants}

The participants were adult patients with MM, from 18year old and above with no age limit. Articles with patients using
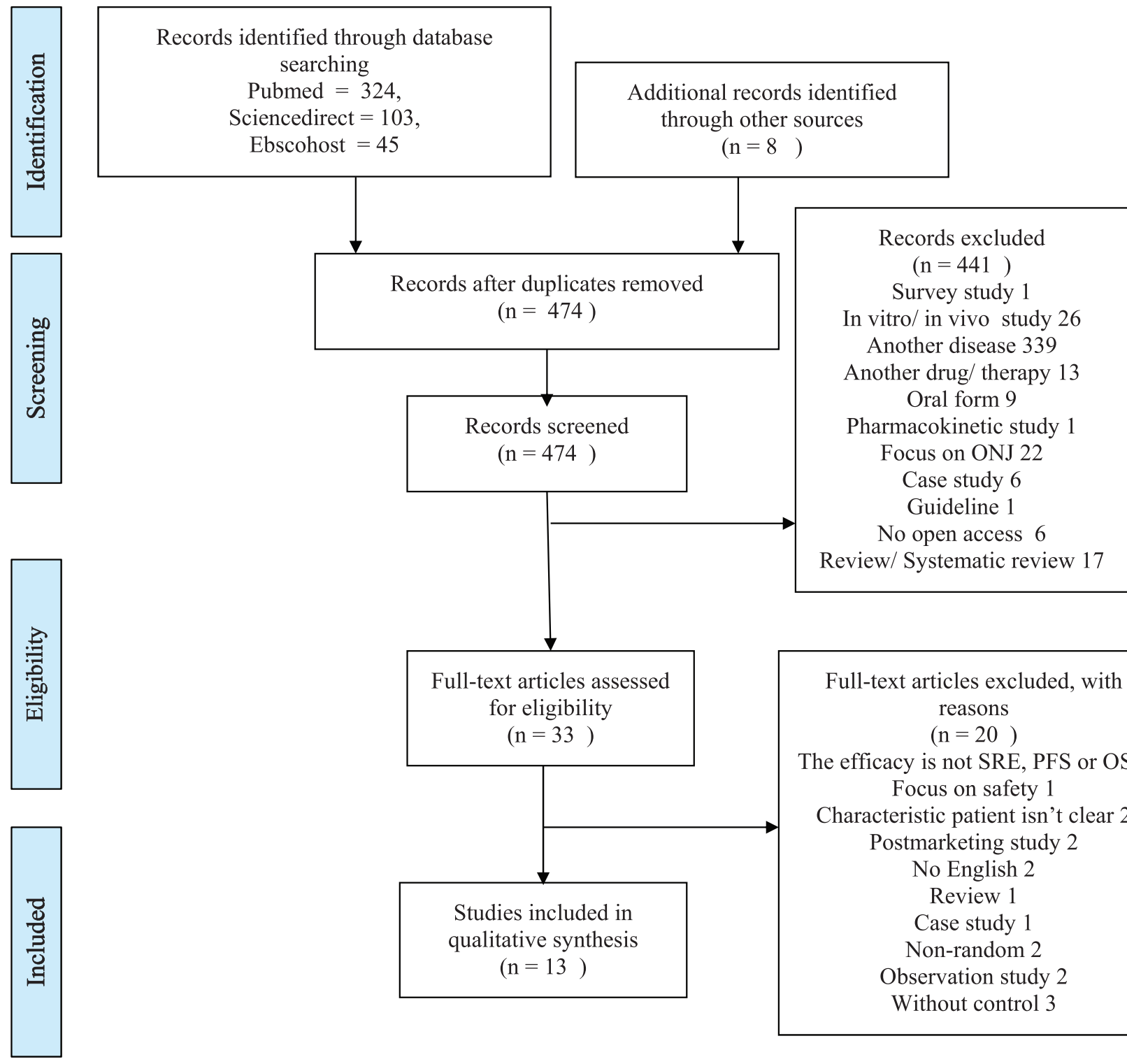

Records after duplicates removed $(n=474)$

Additional records identified through other sources $(\mathrm{n}=8 \quad)$

Figure 1. Selection of inclusive articles in systematic review.

Studies included in qualitative synthesis $(\mathrm{n}=13)$
Full-text articles excluded, with reasons $(\mathrm{n}=20)$

The efficacy is not SRE, PFS or OS 4 Focus on safety 1

Characteristic patient isn't clear 2 Postmarketing study 2

No English 2

Review 1

Case study 1

Non-random 2

Observation study 2

Without control 3 
different treatments as the main intervention and control in terms of using other drugs such as calcium and vitamin D supplements were excluded in the research. However, some articles did not only discuss MM patients but also were selected for review since they have data for MM patients.

\section{Interventions and comparators}

The intervention mainly was intravenous zoledronic acid or ibandronic acid while the comparator was placebo or other bisphosphonates. The dose of zoledronic acid administered was 4 $\mathrm{mg}$ while $2 \mathrm{mg}$ or $4 \mathrm{mg}$ of ibandronic acid was administered.

\section{Outcome}

The clinical outcomes were the incidence of SRE, PFS, OS, as well as some AE, such as ONJ and renal toxicity. The SRE are usually vertebral fractures or other bone fractures, and spinal cord compression, and the need for surgery or radiotherapy to the bone.

\section{Article search method}

The articles were searched in the databases of PUBMED, EBSCOhost, and ScienceDirect. The search was carried out systematically on relevant articles with restrictions to articles published within 1980 and 2018. The keyword for article search was "(ibandronate OR zoledronate) AND (bone metastasis OR metastatic bone disease OR bone pain)". These were limited to free full-text articles written in English.

\section{Article selection and methodological quality assessment}

The selection of the articles was conducted by checking the titles and abstracts of all the articles identified from the literature search results. In situations where the decision of selecting some articles was not reached based on their titles and abstracts, the full texts of such articles were considered in the process. Also, each stage of the search and screening was fully documented with the number of articles included and excluded.

The methodological quality assessment of the articles was conducted using the JADAD Score with a five-point scale, in which 1 and 2 scale are used for low-quality articles and 3 to 5 for high-quality articles.

\section{Data extraction}

The data extracted were tabulated based on the intervention, comparator, patient characteristics, and outcome. However, extraction of the intervention and comparator was performed based on the drug used, the dose and duration of intervention, while the patient characteristics were described in terms of participants' number, gender, cancer type, and MM stage. Finally, the data extraction of outcome was based on the proportion of incident of SRE, AE, PFS, and OS.

\section{RESULTS AND DISCUSSION}

\section{Selected articles and their characteristics}

In total, 13 selected articles through the RCTs met the inclusion criteria as shown in Figure 1. Comparison was conducted between zoledronic and pamidronic acid in three articles (Berenson et al., 2002; Rosen et al., 2001; 2003), three articles also compared zoledronic acid with placebo (Aviles et al., 2013; 2007; Garcia-Sanz et al., 2015), two articles compared zoledronic acid with clodronate (Morgan et al., 2011; 2010), two articles also compared denosumab with zoledronic acid (Henry et al., 2011; Raje et al., 2016), one research article compared ibandronic acid with placebo (Menssen et al., 2002), one article compared pamidronic with ibandronic acid (Terpos et al., 2003), and the last article compared zoledronic acid in every 12 weeks duration with every 4 weeks (Himelstein et al., 2017).

Five articles were with subjects not only on MM patients; two articles were on MM and breast cancer carcinoma (Berenson et al., 2001; Rosen et al., 2001); two articles were with research subjects in breast cancer and MM (Henry et al., 2011; Rosen et al., 2003), and one article was with subjects of breast and prostate cancer, as well as MM (Himelstein et al., 2017). Among the five articles, only Himelstein et al. (2017) presented data on the effectiveness of drugs in preventing SRE in MM subjects, with number as high as 139 people in each treatment group. The other four articles were added because the number of MM subjects was equivalent for each intervention group and comparator.

The treatment duration using the drug was a minimum of 10-24 months or until regression occurs. Eleven articles were with symptomatic MM as subjects and the research of Himelstein et al. (2017) and Garcia-Sanz et al. (2015) did not specifically explain the MM stage on patient characteristics. The quality of the selected articles was high, with scores between 3 and 5. Details of the explanation about the included articles are presented in Table 1.

\section{Effectiveness of zoledronic acid and ibandronic acid}

Data extraction was done to describe the effectiveness of the two drugs as shown in Table 2.

\section{Effectiveness in reventing SRE}

Four articles were zoledronic acid and placebo-controlled (Aviles et al., 2013; 2007; Garcia-Sanz et al., 2015; Menssen et al., 2002). The zoledronic acid has the capacity to reduce skeletal events compared to placebo by more than $50 \%$ (Aviles et al., 2007; Garcia-Sanz et al., 2015). Also, zoledronic acid was superior to placebo in preventing spinal cord compression (GarciaSanz et al., 2015). Furthermore, the incidence of radiotherapy and pathological fractures was reduced by $50 \%$ in the zoledronic acid group compared with the placebo (Aviles et al., 2007).

According to Berenson et al. (2001), Henry et al. (2011), Raje et al. (2016), and Rosen et al. (2001, 2003), the effectiveness of zoledronic acid was not superior to pamidronic acid or Denosumab in the prevention of SRE. At a median of 3-7 years follow-up, there was a lower SRE in the zoledronic acid group compared with the clodronic acid group. Zoledronic acid was superior to clodronic acid in preventing SRE (Morgan et al., 2011). According to Himelstein et al. (2017), 4 weeks duration of zoledronic acid was more effective than 12 weeks.

Ibandronic acid was not superior to placebo in terms of effectiveness in preventing SRE, as time to first (TTF) SRE of ibandronic acid (438 days) was not much different from placebo (462 days). According to Menssen et al. (2002), the pathological fracture in the ibandronic acid group (90\%) during the first 6 months of follow-up was not much different from placebo $(93 \%)$. Also, 20 patients $(86.9 \%)$ of the pamidronic acid group and 19 
Table 1. Characteristics of the included article in the systematic review.

\begin{tabular}{|c|c|c|c|c|c|c|c|c|}
\hline \multirow[b]{2}{*}{ Article } & \multicolumn{4}{|c|}{ Intervention and comparator } & \multicolumn{3}{|c|}{ Subject's characteristic } & \multirow{2}{*}{$\begin{array}{l}\text { Jadad } \\
\text { score }\end{array}$} \\
\hline & Drug & $\begin{array}{l}\text { Dose and route } \\
\text { administration }\end{array}$ & Time duration & $N$ & $\begin{array}{c}\text { Gender } \\
(\mathbf{M} / \mathbf{F})\end{array}$ & Cancer type & MM Stage & \\
\hline \multirow[t]{2}{*}{ Aviles et al., 2007} & Zoledronic Acid & $4 \mathrm{mg}$ IV every 4 weeks & 24 months & 46 & $26 / 20$ & MM & IIIA, IIIB & 4 \\
\hline & Placebo & & & 48 & $23 / 25$ & & & \\
\hline \multirow[t]{2}{*}{ Aviles et al., 2013} & Zoledronic Acid & $4 \mathrm{mg}$ IV every 4 weeks & 24 months & 151 & $71 / 80$ & MM & II B, IIIA, III B & 5 \\
\hline & Placebo & & & 157 & $85 / 72$ & & & \\
\hline \multirow[t]{2}{*}{ Berenson et al., 2001} & Zoledronic Acid & 4 mg IV every 4 week & 10 months & 67 & $17 / 50$ & MM & III & 8 \\
\hline & Pamidronic Acid & 90 mg IV every 4 week & & 73 & $10 / 63$ & Breast Carcinoma & & \\
\hline \multirow[t]{2}{*}{ Garcia-Sanz et al., 2015} & Zoledronic Acid & $4 \mathrm{mg}$ IV every 4 week & 12 months & 51 & $30 / 21$ & MM & A symptomatic & 4 \\
\hline & Placebo & & & 49 & $26 / 23$ & & $\begin{array}{l}\text { and no specific } \\
\text { stage symptomatic }\end{array}$ & \\
\hline \multirow[t]{2}{*}{ Henry et al., 2011} & Zoledronic Acid & 4 mg IV every 4 week & 24 months & 890 & $552 / 338$ & $\mathrm{MM}$ & NR & 8 \\
\hline & Denosumab & 120 mg SC every 4 week & & 886 & $588 / 328$ & $\begin{array}{l}\text { NSCLC } \\
\text { Except for breast \& prostate cancer }\end{array}$ & & \\
\hline \multirow[t]{2}{*}{ Menssen, 2002} & Ibandronic Acid & $2 \mathrm{mg}$ bolus IV every 4 week & $12-24$ months & 99 & $53 / 46$ & MM & IIA-IIIA & 8 \\
\hline & Placebo & & & 99 & $51 / 48$ & & & \\
\hline \multirow[t]{2}{*}{ Morgan et al., 2010} & Zoledronic Acid & 4 mg IV every 4 week & 24 months or & 981 & $589 / 392$ & MM & I, II, III & 5 \\
\hline & Clodronic Acid & Oral 1600 mg daily & until progression & 979 & $576 / 403$ & & & \\
\hline \multirow[t]{2}{*}{ Morgan et al., 2011} & Zoledronic Acid & $4 \mathrm{mg}$ IV every 4 week & 24 months or & 981 & $589 / 392$ & MM & I, II, III & 5 \\
\hline & Clodronic Acid & Oral $1600 \mathrm{mg}$ daily & until progression & 979 & $576 / 403$ & & & \\
\hline \multirow[t]{2}{*}{ Raje et al., 2016} & Zoledronic Acid & 4 mg IV every 4 week & 24 month & 98 & $54 / 39$ & MM & I-III & 7 \\
\hline & Denosumab & $120 \mathrm{mg} \mathrm{SC}$ every 4 week & & 87 & $57 / 30$ & & & \\
\hline \multirow[t]{2}{*}{ Rosen et al., 2001} & Zoledronic Acid & 4 mg IV every 4 week & 12 month & 563 & $104 / 459$ & MM & III & 8 \\
\hline & Pamidronic Acid & 90 mg IV every 4 week & & 524 & $92 / 464$ & Breast Cancer & & \\
\hline \multirow[t]{2}{*}{ Rosen et al., 2003} & Zoledronic Acid & $4 \mathrm{mg}$ IV every 4 week & 24 month & 564 & NR & MM & III & 8 \\
\hline & Pamidronic Acid & 90 mg IV every 4 week & & 558 & NR & Breast Carcinoma & & \\
\hline \multirow[t]{2}{*}{ Terpos et al., 2003} & Ibandronic Acid & 4 mg IV every 4 week & 14 month & 21 & $12 / 9$ & MM & IIA, IIB, IIIA, IIIB & 3 \\
\hline & Pamidronic Acid & 90 mg IV every 4 week & & 23 & $12 / 11$ & & & \\
\hline \multirow[t]{2}{*}{ Himelstein et al., 2017} & Zoledronic Acid & 4 mg IV every 4 week & 24 month & 911 & $414 / 497$ & $\mathrm{MM}$ & No specific, 199 & 5 \\
\hline & Zoledronic Acid & $4 \mathrm{mg}$ IV every 12 week & & 911 & $428 / 483$ & $\begin{array}{l}\text { Breast Cancer } \\
\text { Prostate Cancer }\end{array}$ & $\begin{array}{l}\text { MM patient per } \\
\text { group. }\end{array}$ & \\
\hline
\end{tabular}

(90.4\%) of the ibandronic acid group showed no progression of bone disease during follow-up; however, pamidronic acid was superior to ibandronic acid in reducing bone resorption, interleukin -6- and $\beta 2$-microglobulin pamidronate (Terpos et al., 2003).

\section{Effectiveness in increasing PFS}

According to Aviles et al. (2017), the 5-year event-free survival (EFS) of the zoledronic acid group was $80 \%$, which is statistically different from the $52 \%$ in the placebo group $(p<0.01)$. Also, Garcia-Sanz et al. (2015) reported that a 3-year PFS in the zoledronic acid was $25 \%$ higher than placebo. More so, the increased PFS for 26 days in the zoledronic acid group was not significantly different from the pamidronic acid group (Rosen et al, 2001). According to Morgan et al. (2010), zoledronic acid significantly increased PFS by $12 \%$ compared to clodronic acid. In terms of median follow-up, PFS of 12 weeks duration of using zoledronic acid was more effective compared with 4 weeks (Himelstein et al., 2017).

\section{Effectiveness in increasing $O S$}

Zoledronic acid was superior to placebo in improving OS and according to Aviles et al. (2017) and Garcia-Sanz et al. (2015), there was an over 50\% increment in the zoledronic acid group than the placebo. The median OS in the zoledronic acid group could not be described during follow-up, while that of the pamidronic acid group was 802 days (Rosen et al, 2001). According to Henry et al. (2011) and Raje et al. (2016), OS and PFS in the zoledronic acid and denosumab groups were equivalent.

The overall median survival in the ibandronic acid group (33.1 months) was not significantly different compared with the placebo (28.2 months). However, a research conducted by Menssen et al. (2002) stated that a small subgroup of 39 patients with WHO scored 2 to 4 at baseline and patients with VAS scores between 2 and 4 experienced significant survival benefits when treated with ibandronic acid $(p<0.03)$ and patients with radiotherapy at baseline have longer life span in the ibandronate group $(p<0.24 \%)$.

\section{Safety of zoledronic acid and ibandronic acid}

The safety data of the drugs extracted are shown in Table 3. According to Garcia-Sanz et al. (2015), the incidence of ONJ in zoledronic acid group was greater compared with the placebo. More so, the incidence of ONJ in zoledronic acid group was not much different from the denosumab (Henry et al., 2011). 


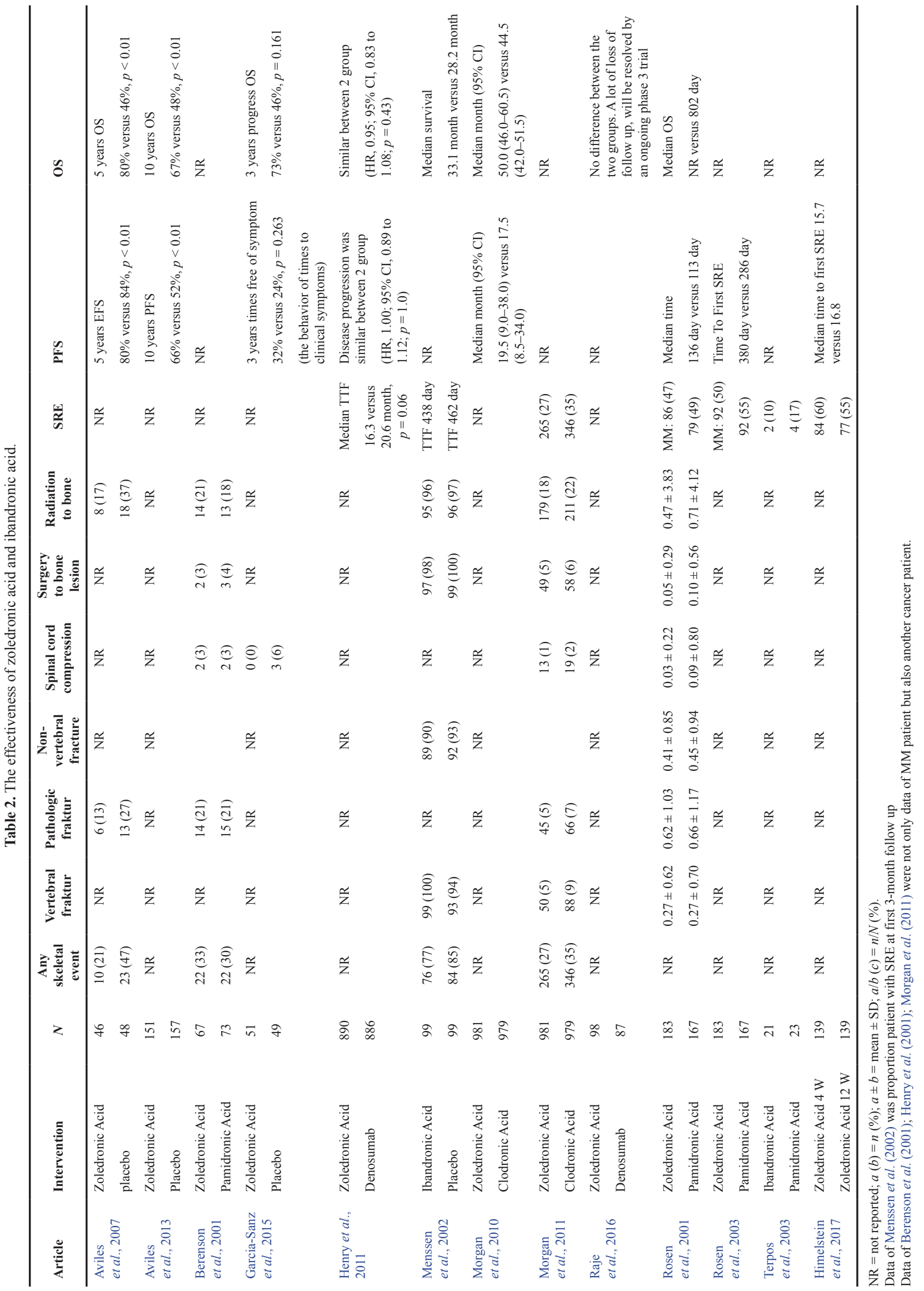


Table 3. Safety of zoledronic acid or ibandronic acid.

\begin{tabular}{|c|c|c|c|c|}
\hline Article & Intervention & $N$ & $\begin{array}{c}\text { Osteonecrosis of the Jaw } \\
n(\%)\end{array}$ & $\begin{array}{c}\text { Renal Toxicity } \\
n(\%)\end{array}$ \\
\hline \multirow[t]{2}{*}{ Aviles et al., 2007} & Zoledronic Acid & 46 & NR & NR \\
\hline & placebo & 48 & & \\
\hline \multirow[t]{2}{*}{ Aviles et al., 2013} & Zoledronic Acid & 151 & NR & NR \\
\hline & Placebo & 157 & & \\
\hline \multirow[t]{2}{*}{ Berenson et al., 2001} & Zoledronic Acid & 67 & NR & NR \\
\hline & Pamidronic Acid & 73 & & \\
\hline \multirow[t]{2}{*}{ Garcia-Sanz et al., 2015} & Zoledronic Acid & 51 & $1(2)$ & $1(2)$ \\
\hline & Placebo & 49 & $0(0)$ & $2(4)$ \\
\hline \multirow[t]{2}{*}{ Henry et al., 2011} & Zoledronic Acid & 878 & $11(1.3)$ & $96(10.9)$ \\
\hline & Denosumab & 878 & $10(1.1)$ & $73(8.31)$ \\
\hline \multirow[t]{3}{*}{ Menssen et al., 2002} & Ibandronic Acid & 99 & NR & Only hypocalcemia, no clinically \\
\hline & Placebo & 99 & & $\begin{array}{l}\text { relevant differences were found in } \\
\text { urinary safety available }\end{array}$ \\
\hline & & & & Acute renal failure \\
\hline \multirow[t]{6}{*}{ Morgan et al., 2010} & Zoledronic Acid & 981 & $21(4)$ & $29(5)$ \\
\hline & Clodronic Acid & 979 & $2(<1)$ & $33(6)$ \\
\hline & & & & Renal and urinary disorders \\
\hline & Zoledronic Acid & 981 & & $7(1)$ \\
\hline & Clodronic Acid & 979 & & $8(1)$ \\
\hline & & & & Acute renal failure \\
\hline \multirow[t]{3}{*}{ Morgan et al., 2011} & Zoledronic Acid & 981 & $35(4)$ & $57(6)$ \\
\hline & Clodronic Acid & 979 & $3(<1)$ & $60(6)$ \\
\hline & & & & Hypocalcemia \\
\hline \multirow[t]{2}{*}{ Raje et al., 2016} & Zoledronic Acid & 98 & $2(2)$ & $10(11)$ \\
\hline & Denosumab & 87 & $4(5)$ & $12(14)$ \\
\hline \multirow[t]{2}{*}{ Rosen et al., 2001} & Zoledronic Acid & 524 & NR & NR \\
\hline & Pamidronic Acid & 555 & & \\
\hline \multirow[t]{3}{*}{ Rosen et al., 2003} & Zoledronic Acid & 524 & NR & NR \\
\hline & Pamidronic Acid & 555 & & \\
\hline & & & & Hypocalcemia: \\
\hline \multirow[t]{2}{*}{ Terpos et al., 2003} & Ibandronic Acid & 23 & NR & $0(0)$ \\
\hline & Pamidronic Acid & 21 & & $2(9)$ \\
\hline \multirow[t]{2}{*}{ Himelstein et al., 2017} & Zoledronic Acid $4 \mathrm{~W}$ & & 18/911 (2) & 10/852 (12) \\
\hline & Zoledronic Acid $12 \mathrm{~W}$ & & 9/911 (1) & 4/837 (0.5) \\
\hline
\end{tabular}

In addition, Raje et al. (2016) reported more cases of ONJ in the zoledronic acid group than the denosumab. Furthermore, there was more occurrence of $\mathrm{ONJ}$ in the zoledronic acid group than clodronate (Morgan et al., 2011). Also, 12 weeks duration of using zoledronic acid reduced ONJ more than the 4 weeks (Himelstein et al, 2017). According to Garcia-Sanz et al. (2015) and Morgan et al. $(2011,2010)$, renal toxicity in the zoledronic acid group was not different with the placebo and clodronate groups; however, the renal toxicity was higher than the denosumab group according to Henry et al. (2011).

Menssen et al. (2002) and Terpos et al. (2003) reported the possibility of detecting hypocalcemia after 4 weeks of ibandronic acid injection. In overall, the AE in the ibandronic acid group was the same with the placebo (Menssen et al., 2002) and
ONJ was not reported in any of the ibandronic acid groups of the selected articles.

\section{DISCUSSION}

Zoledronic and ibandronic acids are important supportive therapies in the treatment of MM; however, there were limited evidence in the comparison of these two drugs. This study conducted a systematic review of the effectiveness of zoledronic and ibandronic acid in MM patients with intervention periods of 10-24 months. Pozzi and Raje (2011) stated that the optimal treatment duration with the use of bisphosphonates was indeed debatable but its long-term use needs to be alerted due to the occurrence of ONJ. Some guidelines suggest monthly use for 2 years based on follow-up results (laboratory data, patient 
response, patient disease stability, relapse, or progression of bone disease). The Mayo Clinic guidelines suggest a monthly treatment for 2 years, terminated in patients who achieve remission or stable disease, then continue every 3 months in patients who still need more treatment. However, the International Myeloma Working Group (IMWG) stated something contrary. According to IMWG, the treatment duration of bisphosphonate needs to be adapted based on the status of the bone disease. According to Pozzi and Raje (2011), the additional use every 3 months in patients in need of more treatment or with the active bone disease was not been supported by data from the study.

Based on the systematic review, it was discovered that zoledronic acid was superior in preventing SRE compared with placebo and clodronate but not superior to other bisphosphonate compounds such as pamidronic acid and denosumab. The data for OS and PFS in the zoledronic acid group were also in line with their ability in preventing SRE.

More so, the effectiveness of ibandronic acid in preventing SRE was not superior to placebo and pamidronic acid (Menssen et al., 2002; Terpos et al., 2003). Likewise, ibandronic acid was effective in inhibiting bone resorption, interleukin-6 and $\beta 2$-microglobulin, just as pamidronic acid. There was no reported data of OS and PFS with the use of ibandronic acid in the thirteen articles. This is in accordance with the statement of Geng et al. (2015), that ibandronic acid treats patients with metastatic breast cancer by inhibiting osteoclast activity and bone resorption, which are capable of causing osteoclast apoptosis.

However, there were more cases of $\mathrm{AE}$ with the use of zoledronic acid in patients compared with ibandronic acid. Based on these, it could be concluded that zoledronic acid was more effective than ibandronic acid in preventing SRE but with more occurrence of AE. Also, there were more occurrence of renal toxicity with the use of zoledronic acid. A retrospective study by Weide et al. (2010) with 84 MM patients who received zoledronic and ibandronic acid therapies showed that ibandronic acid produced a better renal profile than zoledronate acid. More so, there was more occurrence of the incidence ONJ and kidney damage with the use of zoledronic acid compared with ibandronic acid (Delea et al., 2012; Weide et al., 2010). The safety results of ibandronic acid in the kidneys could be used as a basis for its use for MM patients with high creatinine levels or renal disease.

ONJ was an AE associated with the use of bisphosphonates, which was first identified in 2003, several years after the introduction of pamidronic and zoledronic acids in clinical therapy (Pozzi and Raje, 2011). Some guidelines for the use of bisphosphonate compounds stated that if an ONJ case occurs, therapy must be stopped immediately until it is cured. According to Alegre et al. (2013), the use of zoledronic acid could be repeated as soon as the patient recovers. However, Himelstein's data (2017) showed that the incidence of AE can be reduced by extending the duration of administering zoledronic acid in each cycle. Also, there is a need for the determination of creatinine serum levels as long as zoledronic acid is used (Himelstein et al., 2017). More so, there is need to assess other clinical symptoms and blood tests every 3 months to examine other clinical data such as electrolytes, serum calcium levels, and albuminuria (Alegre et al., 2013).
The results of this research were in line with the systematic review conducted by Palmieri et al. (2013), which stated that zoledronic acid was more potent in the treatment of bone metastases compared with ibandronic acid. It was also considered with several MM therapy guidelines that more recommended the use of zoledronic acid than other bisphosphonates in preventing SRE. Some of the latest cancer therapy guidelines recommend zoledronic acid for the early stages of MM with the recommended dose of $4 \mathrm{mg}$ IV in 15 minutes of infusion every 4 weeks. Higher doses were not recommended because of its toxicity. The treatment duration was 2 years which could be continued if the patient's needs more treatment (Alegre et al., 2013).

The effectiveness of zoledronic acid compared to ibandronic acid in this systematic review needs to be studied head-to-head in order to maintain the hypothesis that zoledronate is actually more effective in use in clinical practice.

\section{CONCLUSION}

In all, zoledronic acid was more effective than ibandronic acid as bone metastases therapy in MM. ONJ was more common with the use of zoledronic acid and the AE in the zoledronic acid group could be reduced by extending the treatment duration.

\section{FINANCIAL SUPPORT}

The research is a part of pharmacoeconomics study that supports by the Indonesian Health Ministry Scholarship.

\section{CONFLICT OF INTEREST}

The authors declared that there is no conflict of interest.

\section{REFERENCES}

Alegre A, Gironella M, Alicia B, Giraldo P. Zoledronic acid in the management of bone disease as a consequence of multiple myeloma: a review. Eur J Haematol, 2013; 92:181-8.

Aviles A, Nambo M.J, Neri N, Castañeda C, Cleto S, HuertaGuzmán J. Antitumor effect of zoledronic acid in previously untreated patients with multiple myeloma. Med Oncol, 2007; 24:227-30.

Aviles A, Neri N, Huerta-Guzman J, Nambo MJ. Randomized clinical trial of zoledronic acid in multiple myeloma patients undergoing high-dose chemotherapy and stem-cell transplantation. Curr Oncol, 2013; 20:e13-20.

Berenson J, Hillner B, Kyle R, Anderson K, Lipton A, Yee G, Biermann S. American society of clinical oncology clinical practice guidelines: the role of bisphosphonates in multiple myeloma. J Clin Oncol, 2002; 20:3719-36.

Berenson JR, Rosen LS, Howell A, Porter L, Coleman RE, Morley W, Dreicer R, Kuross SA, Lipton A, Seaman JJ. Zoledronic acid reduces skeletal-related events in patients with osteolytic metastases: a double-blind, randomized dose-response study. Cancer, 2001; 91:1191-200.

Delea T, Rotter J, Taylor M, Chandiwana D, Bains M, El Ouagari K, Kaura S, Morgan G. Cost-effectiveness of zoledronic acid vs clodronic acid for newly diagnosed multiple myeloma from the United Kingdom healthcare system perspective. Curr Oncol, 2012; 19:392-402.

Gabbert T, Hoffmeister B, Felsenberg D. Risk factors influencing the duration of treatment with bisphosphonates until occurrence of an osteonecrosis of the jaw in 963 cancer patients. J Cancer Res Clin Oncol, 2014; 141:749-58

Garcia-Sanz R, Oriol A, Moreno MJ, de la Rubia J, Payer AR, Hernandez MT, Palomera L, Teruel AI, Blanchard MJ, Gironella M, Ribas P, Bargay J, Abella E, Granell M, Ocio EM, Ribera JM, San Miguel JF, Mateos MV, Spanish Myeloma Group (GEM/PETHEMA). Zoledronic 
acid as compared with observation in multiple myeloma patients at biochemical relapse: results of the randomized AZABACHE Spanish trial. Haematologica, 2015; 100:1207-13.

Geng CJ, Liang Q, Zhong JH, Zhu M, Meng FY, Wu N, Liang R, Yuan BY. Ibandronate to treat skeletal-related events and bone pain in metastatic bone disease or multiple myeloma: a meta-analysis of randomized clinical trials. BMJ Open 5, 2015; e007258:1-10.

Henry DH, Costa L, Goldwasser F, Hirsh V, Hungria V, Prausova J, Scagliotti GV, Sleeboom H, Spencer A, Vadhan-Raj S, von Moos R, Willenbacher W, Woll PJ, Wang J, Jiang Q, Jun S, Dansey R, Yeh H. Randomized, double-blind study of denosumab versus zoledronic acid in the treatment of bone metastases in patients with advanced cancer (excluding breast and prostate cancer) or multiple myeloma. J Clin Oncol, $2011 ; 29: 1125-32$.

Himelstein A, Foster J, Khatcheressia J, Roberts J, Seisler D, Novotny P, Qin R, Go R, Grubss S, O'connor T, Velasco M, Weckstein D. Effect of longer-interval vs standard dosing of zoledronic acid on skeletal events in patients with bone metastases: a randomized clinical trial. JAMA, $2017 ; 317: 48-58$

Menssen HD, Sakalová A, Fontana A, Herrmann Z, Boewer C, Facon T, Lichinitser MR, Singer CRJ, Euller-Ziegler L, Wetterwald M, Fiere D, Hrubisko M, Thiel E, Delmas PD. Effects of long-term intravenous ibandronate therapy on skeletal-related events, survival, and bone resorption markers in patients with advanced multiple myeloma. J Clin Oncol, 2002; 20:2353-9.

Morgan GJ, Child JA, Gregory WM, Szubert AJ, Cocks K, Bell SE, Navarro-Coy N, Drayson MT, Owen RG, Feyler S, Ashcroft AJ, Ross FM, Byrne J, Roddie H, Rudin C, Cook G, Jackson GH, Wu P, Davies FE. Effects of zoledronic acid versus clodronic acid on skeletal morbidity in patients with newly diagnosed multiple myeloma (MRC Myeloma IX): secondary outcomes from a randomized controlled trial. Lancet Oncol, $2011 ; 12: 743-52$.

Morgan GJ, Davies FE, Gregory WM, Cocks K, Bell SE, Szubert AJ, Navarro-Coy, Drayson MT, Owen RG, Feyler S, Ashcroft AJ, Ross FM, Byrne J, Roddie H, Rudin C, Cook G. First-line treatment with zoledronic acid as compared with clodronic acid in multiple myeloma (MRC Myeloma IX): a randomized controlled trial. Lancet, 2010; 376:1989-99.

NCCN. Multiple myeloma (NCCN Guideline for patients). NCCN.org, Fort Washington, , 2018.

Palmieri C, Fullarton JR, Brown J. Comparative efficacy of bisphosphonates in metastatic breast and prostate cancer and multiple myeloma: a mixed treatment meta-analysis. Clin Cancer Res, 2013; 19(24):6863-72.

Pozzi S, Raje N. The role of bisphosphonates in multiple myeloma: mechanisms, side effects, and the future. Oncologist, 2011; $16: 651-62$.

Raje N, Vadhan-Raj S, Willenbacher W, Terpos E, Hungria V, Spencer A, Alexeeva Y, Facon T, Stewart AK, Feng A, Braun A, Balakumaran A, Roodman GD. Evaluating results from the multiple myeloma patient subset treated with denosumab or zoledronic acid in a randomized phase 3 trial. Blood Cancer J, 2016; 6:e378-e378.

Rosen L, Gordon, D, Kaminsky M, Howell A, Belch K, Mackey J, Apffelstaedt J, Hussein M, Coleman RE, Reitsma D. Zoledronic acid versus pamidronate in the treatment of skeletal metastases in patients with breast cancer or osteolytic lesions of multiple myeloma: a phase III, doubleblind, comparative trial. Cancer J, 2001; 7: 377-87.

Rosen LS, Gordon D, Kaminski M, Howell A, Belch A, Mackey J, Apffelstaedt J, Hussein MA, Coleman RE, Reitsma DJ, Chen BL, Seaman JJ. Long-term efficacy and safety of zoledronic acid compared with pamidronate disodium in the treatment of skeletal complications in patients with advanced multiple myeloma or breast carcinoma: a randomized, double-blind, multicenter, comparative trial. Cancer, 2003; 98:1735-44.

Saroja K, Ram VM. Arthralgia - the principal side effect in breast cancer patients receiving aromatase inhibitors and its management. J Appl Pharm Sci, 2017; 7:111-4.

Terpos E, Viniou N, De la fuente J, Meletis J, Voskaridou E, Karkantaris C, Vaiopoulos G, Palermos J, Yataganas X, Goldman J, Rahemtulla A. Pamidronate is superior to ibandronate in decreasing bone resorption interleukin-6 and b 2-microglobulin in multiple myeloma. Eur J Haematol, 2003; 70:34-42.

Union for International Cancer Control. 2016. Bisphosphonate therapy (2016 Review of cancer medicines on the WHO list of essential medicines). Available via https://www.who.int/selection_medicines/ committees/expert/21/applications/s8_zoledronic_acid_add.pdf?ua=1. (Accessed 1 March 2019).

Weide R, Koppler H, Antras L, Michael S, Chang E, Green J, Wintfeld N. Renal toxicity in patients with multiple myeloma receiving zoledronic acid vs. ibandronate: a retrospective medical records review. J Cancer Res Ther, 2010; 6:31-5.

How to cite this article:

Sayuti NA, Andayani TM, Endarti D, Hariadi KWT. The effectiveness of zoledronic acid and ibandronic acid as therapy for bone metastases in multiple myeloma: A systematic review. J Appl Pharm Sci, 2019; 9(11):118-125. 